\title{
The RISKMED project: philosophy, methods and products
}

\author{
A. Bartzokas ${ }^{1}$, J. Azzopardi ${ }^{2}$, L. Bertotti ${ }^{3}$, A. Buzzi ${ }^{4}$, L. Cavaleri ${ }^{3}$, D. Conte $^{5}$, S. Davolio ${ }^{4}$, S. Dietrich $^{6}$, A. Drago $^{2}$, \\ O. Drofa ${ }^{4}$, A. Gkikas ${ }^{1}$, V. Kotroni ${ }^{7}$, K. Lagouvardos ${ }^{7}$, C. J. Lolis ${ }^{1}$, S. Michaelides ${ }^{8}$, M. Miglietta ${ }^{5}$, A. Mugnai ${ }^{6}$,

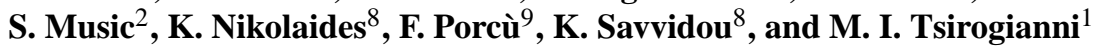 \\ ${ }^{1}$ Laboratory of Meteorology, Department of Physics, University of Ioannina, Ioannina, Greece \\ ${ }^{2}$ IOI - Malta Operational Centre/Physical Oceanography Unit, University of Malta, Msida, Malta \\ ${ }^{3}$ Institute of Marine Sciences - National Research Council, Venice, Italy \\ ${ }^{4}$ Institute of Atmospheric Sciences and Climate - National Research Council, Bologna, Italy \\ ${ }^{5}$ Institute of Atmospheric Sciences and Climate - National Research Council, UOS Lecce, Lecce, Italy \\ ${ }^{6}$ Institute of Atmospheric Sciences and Climate - National Research Council, Roma, Italy \\ ${ }^{7}$ Institute of Environmental Research, National Observatory of Athens, Athens, Greece \\ ${ }^{8}$ Cyprus Meteorological Service, Nicosia, Cyprus \\ ${ }^{9}$ Department of Physics, University of Ferrara, Ferrara, Italy
}

Received: 5 February 2010 - Revised: 17 May 2010 - Accepted: 23 May 2010 - Published: 1 July 2010

\begin{abstract}
This paper presents RISKMED, a project targeted to create an Early Warning System (EWS) in case of severe or extreme weather events in the central and eastern Mediterranean and specifically in southern Italy, northwestern Greece, Malta and Cyprus. As severe or extreme weather events are considered, cases when the values of some meteorological parameters (temperature, wind, precipitation) exceed certain thresholds, and/or a severe weather phenomenon (thunderstorm, snowfall) occurs. For an accurate weather forecast, selected meteorological models have been operated daily, based on a nesting strategy using two or three domains, providing detailed forecasts over the above mentioned areas. The forecast results are further exploited for the evaluation and prediction of human discomfort and fire weather indices. Finally, sea wave models have also been operating daily over the central and eastern Mediterranean Sea. In case a severe or extreme weather event is forecasted within the next 48 or $72 \mathrm{~h}$ for selected target areas (sub-regions defined by their morphological and population characteristics), the local authorities and the public are informed via a user-friendly graphic system, the so-called RISK MAP. On the web page of the Project (http://www.riskmed.net), additional information is provided about the real-time values of some meteorological parameters, the latest satellite picture and the time and space distribution of lightning during the last $24 \mathrm{~h}$. The RISKMED project was financed by the EU and
\end{abstract}

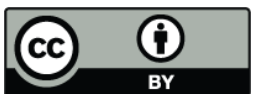

Correspondence to: A. Bartzokas (abartzok@uoi.gr) the Ministries of National Economy of Greece, Italy, Malta and Cyprus, in the frame of INTERREG IIIB/ARCHIMED programme.

\section{Introduction}

Extreme and severe weather events have an adverse impact to humans as well as to a variety of their social and economic activities. During the last decade, an increasing number of weather-associated disasters forewarn scientists and politicians of future challenges. Since most climate change scenarios, apart from temperature increase, also foresee a further increase in the frequency and intensity of severe weather events, researchers are focusing on developing methodologies for disaster risk reduction (see e.g. Novac, 2007; Auld, 2008; Rauhala and Schultz, 2009). The results of such research activities, which in most cases are adopted by the National Meteorological Services, may prove valuable in the effort to minimize natural hazards and loss of lives in the future. The RISKMED Project - "Weather Risk Reduction in the Central and Eastern Mediterranean", constitutes an applied research in this direction, focused on the central and eastern Mediterranean.

The Mediterranean is an area well-known for severe weather events, mainly due to the formation of Mediterranean storms especially in autumn and winter, but also for the occurrence and persistence of high surface temperatures (heat waves) during summer. In order to address these problems, the accurate prediction of adverse weather events and

Published by Copernicus Publications on behalf of the European Geosciences Union. 
the dissemination of warnings to the relevant authorities and the public is a very important, but also a demanding task. Therefore, the main objective of RISKMED is to build an Early Warning System (EWS) that provides accurate and detailed weather forecasts and disseminates the corresponding warnings. Apart from this, the daily evaluation of some human discomfort and forest fire indices and the forecast of wave height for specific areas in the central and eastern Mediterranean Sea are other parallel objectives of the Project.

In order to meet these objectives, a solid partnership has been attained comprising scientific groups and end-users from Greece, Italy, Malta and Cyprus; specifically, the University of Ioannina (Lead Partner) and the Region of Epirus, in Greece, the Institute of Atmospheric Science and Climate of the Italian National Research Council (ISAC-CNR) and the Region of Calabria, in Italy, the University of Malta and the Cyprus Meteorological Service. Moreover, the Institute of Environmental Research of the National Observatory of Athens (NOA), Greece and the Institute of Marine Sciences (ISMAR-CNR), Italy, were involved in the Project as subcontractors. The scientific partners have built a system capable of producing detailed atmospheric and marine forecasts, based on high-resolution, numerical weather and wave models, respectively, while at the same time real-time satellite and lightning observations are also provided. In collaboration with the end-users of the project (regional authorities and civil defense agencies), the forecasts of weather, wave and risk indices are tailored according to their specific needs and the final EWS has been constructed and implemented operationally in demonstrating mode. The RISKMED EWS appears today as a powerful tool for the protection of life and property from adverse weather conditions, since the whole system has remained operational even after the completion of the project. The results, namely, forecasts, warnings as well as other significant information, are made available to everyone via the official web site of the project: http://www.riskmed.net.

At this point, it is worth mentioning other projects that also built real-time nowcasting and forecasting systems. Namely, the EU funded project FLASH (Price et al., 2010; Yair et al., 2010) has been focused on studying flash floods in the Mediterranean, while trying to improve short-term (hours) and mid-term (days) forecasts of heavy precipitation events across the Mediterranean and Europe. Indeed, the project partnership has developed and supplied tools for nowcasting and forecasting that are freely available to end-users and stakeholders (www.flashproject.org).

The RISKMED project was financed in the framework of the INTERREG IIIB/ARCHIMED programme, by the European Regional Development Fund (50-75\%) and by the Ministries of National Economy of Greece, Italy, Malta and Cyprus (25-50\%). The present paper is intended to give a general introduction to RISKMED, while more detailed information is given in the other publications of the same spe- cial issue of this journal (Bertotti et al., 2009; Bertotti and Cavaleri, 2009; Davolio et al., 2009; Savvidou et al., 2009; Bartzokas et al., 2010; Casella et al., 2010; Dietrich et al., 2010; Drago et al., 2010; Mugnai et al., 2010).

\section{Methodologies}

The first task undertaken by the six project partners and the two sub-contractors was to generate a working definition of the term "severe weather events". This definition is based on the needs of the end users and the ability of the available forecasting systems. It was decided that warnings would be issued in six cases: very high temperatures, very low temperatures, strong winds, heavy precipitation, thunderstorms, and snowfalls. Other, equally adverse, phenomena may be either very local, not easily predicted (e.g. hail storms), or not forecasted by the models used in the present research (e.g. dust storms), and therefore they are not considered. Then, corresponding threshold values have been defined for issuing the warnings. To attain this aim, the end-users provided the scientific group with a series of records of natural hazards (floods, severe storms, heat waves, prolonged frosts, etc.), which had taken place in the areas of their responsibility, over a long time period. These data, along with the meteorological and climatological archives of the scientific institutions, constituted the basis for the definition of the warning thresholds. Each country defined its own thresholds based on specific local characteristics, as for example, mean weather conditions, geomorphology, people employment, etc. Furthermore, some countries set the same values for the various sub-areas, while others opted for different values. As for the levels for issued warnings, it was decided to adopt the three-level warning system utilised by the Network of the European Meteorological Services in Meteoalarm (http://www.meteoalarm.eu), viz. yellow, orange and red, since internet users and local authorities are already familiar with this subdivision. More specific details on the thresholds defined, for each parameter and for each study region, can be found in the above mentioned papers of the same special issue as well as on the web site of the project.

The target areas of the project are: Epirus (northwestern Greece), Puglia and Calabria (southern Italy), Malta and Cyprus (Fig. 1). The main advantage and innovation of the present work is the issuance of warnings for sub-divisions of the above areas (up to $25 \times 25 \mathrm{~km}$ ) that are much smaller than the target regions considered in Meteoalarm and in other national warning systems. It is obvious that, although the probability of success of a warning of, for example, heavy rainfall over a large area (e.g. $150 \times 150 \mathrm{~km}$ ) is a priori higher, in practice it is not as useful as a warning issued for particular sub-areas alone. The number and the size of the sub-areas of each country (or region) were also defined independently by the partners, taking into account their morphological and population characteristics. Thus, the mountainous northwestern Greece was divided into 16 sub-areas, 


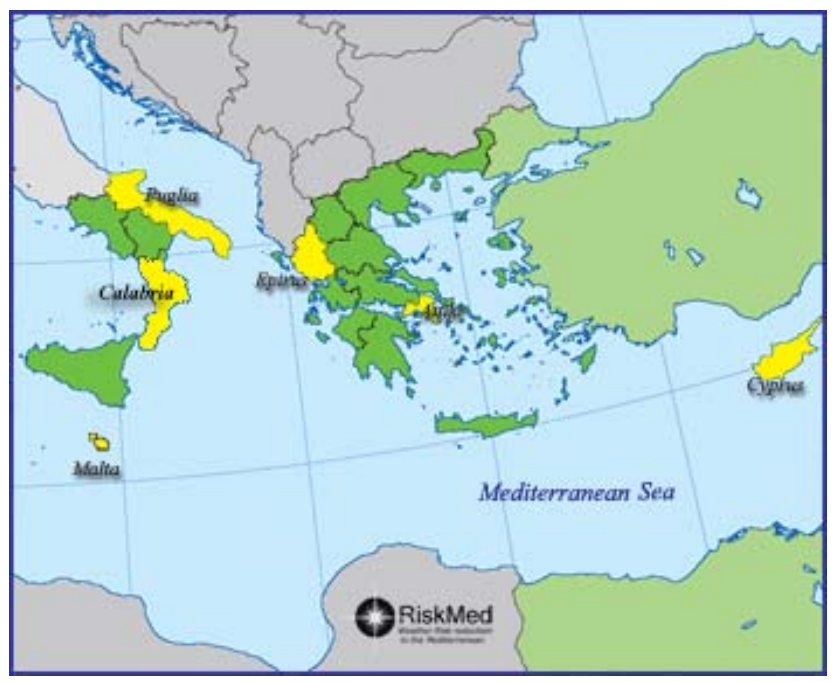

Fig. 1. The target areas of the RISKMED project (in yellow).

southern Italy in 14 (3 in Puglia, 6 in Calabria, 1 in the Adriatic Sea, 3 in the Ionian Sea and 1 in the Tyrrhenian Sea), Malta in 9 ( 1 over the islands Malta and Gozo and 8 over the sea areas around them) and Cyprus in 9 (1 covering the central part of the island, 1 covering the sea only south of the island and 7 covering the coastal areas).

For a successful EWS, high resolution weather forecasts are carried out for the areas above, adopting a nesting technique using two or three domains. The inner domains have typically a $2-4 \mathrm{~km}$ horizontal grid increment. Different operational and research weather models are employed since some partners have been using their own models (with a lower resolution) for a long time. The models used are MM5, BOLAM, MOLOCH, WRF, and MARIA/ETA. All models are initialized using the 00:00 UTC gridded analysis fields and 6-h interval forecasts (0.5 or 1-degree lat./lon. resolution) provided by the Global Forecast System (GFS) of NOAA/NCEP (USA). The simulations for the inner domains are provided at 2 or $3 \mathrm{~h}$ interval for lead times up to 48 or $72 \mathrm{~h}$. Forecasts verification, a very important process for such a forecasting system, has been also carried out and is provided in the aforementioned RISKMED articles published in the same issue.

The models, implemented for each target area, are as follows:

i) For the application in the Epirus region, the nonhydrostatic model MM5 v. 3.6, (Dudhia, 1993) is used. MM5 allows the selection among a large number of parameterization schemes of various physical processes. In the present study, the microphysical scheme described by Schultz (1995) and the convective parameterization scheme of Kain and Fritsch (1993) were adopted. After testing the implementation of many schemes, this selection was found to be the best for the
Greek area (Kotroni and Lagouvardos, 2001, 2004). For the atmospheric boundary layer, the scheme of Hong and Pan (1996), known as MRF scheme, is used. The selection of MRF scheme was based on findings of Akylas et al. (2007), who compared the MM5 operational forecasts over Athens with three different atmospheric boundary layer schemes for the warm period of 2002. They found that the MRF scheme produced the best forecasts in terms of near-surface temperature. Weather forecasts are performed on a daily basis, using the following one-way nesting strategy: grid $1(24 \mathrm{~km}$ horizontal grid increment) covers most of Europe and the Mediterranean, grid 2 ( $8 \mathrm{~km}$ horizontal grid increment) covers Greece and the surrounding sea areas, while grid 3 ( $2 \mathrm{~km}$ horizontal grid increment) covers the Epirus area and the northeastern Ionian Sea. Grids 1 and 2 simulations cover a 72-h period while grid 3 a 48-h period.

ii) For the application in southern Italy, the two independent modelling systems BOLAM-MOLOCH and WRF have been implemented. The hydrostatic model BOLAM and the non-hydrostatic model MOLOCH have been developed at ISAC-CNR as a tool for short-range weather prediction and research studies. A detailed description of the modelling systems is found in Davolio et al. (2007). The Weather Research and Forecasting (WRF) Model (Michalakes et al., 2005; Skamarock et al., 2005; see also www.wrf-model.org) has been implemented selecting the Thompson et al. (2004) microphysics, the Kain and Fritsch (1993) convective scheme and the Yonsei University (YSU) boundary layer scheme (Hong and Pan, 1996). The implementation of a dual-model chain allows for a more flexible approach and for a direct comparison of the model outputs. Similar domains and resolutions have been chosen for the two different modelling systems. The largest domain (16 km horizontal resolution), which covers approximately the central Mediterranean basin, represents the integration area for BOLAM and WRF (coarse resolution domain). The inner domain (4 km horizontal resolution) covers the entire southern Italy and adjacent seas, covering the Puglia and Calabria regions. The higher resolution simulations are provided by a one-way nesting of MOLOCH into BOLAM and a twoway self-nesting for WRF. For the low-resolution integration (BOLAM and WRF outer grids), moist convection is parameterized, while for the higher resolution grid (MOLOCH and WRF inner grid), the deep-moistconvection parameterization is switched off. The forecast range is $72 \mathrm{~h}$ for all the three models. With a similar implementation, the modelling systems were able to simulate in an accurate way some extreme weather events over Puglia region (Davolio et al., 2009; Miglietta and Regano, 2008). 
Table 1. Operational features of the implemented models.

\begin{tabular}{|c|c|c|c|}
\hline & Target areas & Models - Grid resolution & Boundary conditions \\
\hline \multirow{4}{*}{ 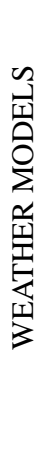 } & NW Greece & $\begin{array}{l}\text { MM5 (Europe }-24 \mathrm{~km} \times 24 \mathrm{~km}) \\
\text { MM5 (Greece }-8 \mathrm{~km} \times 8 \mathrm{~km}) \\
\text { MM5 (Epirus }-2 \mathrm{~km} \times 2 \mathrm{~km})\end{array}$ & GFS \\
\hline & S. Italy & $\begin{array}{l}\text { BOLAM }\left(\mathrm{C} \text {. Mediterranean }-0.15^{\circ} \times 0.15^{\circ}\right) \\
\text { MOLOCH }\left(\text { S. Italy }-0.035^{\circ} \times 0.035^{\circ}\right) \\
\text { WRF }(\mathrm{C} \text {. Mediterranean }-16 \mathrm{~km} \times 16 \mathrm{~km}) \\
\text { WRF }(\text { S. Italy }-4 \mathrm{~km} \times 4 \mathrm{~km})\end{array}$ & GFS \\
\hline & Malta & $\begin{array}{l}\text { MARIA/ETA }\left(\text { Mediterranean }-0.17^{\circ} \times 0.17^{\circ}\right) \\
\text { MARIA/ETA }\left(\text { C. Mediterranean }-0.042^{\circ} \times 0.042^{\circ}\right)\end{array}$ & GFS \\
\hline & Cyprus & $\begin{array}{l}\text { BOLAM }\left(\text { E. Mediterranean }-0.21^{\circ} \times 0.21^{\circ}\right) \\
\text { BOLAM }\left(\text { Cyprus }-0.07^{\circ} \times 0.07^{\circ}\right)\end{array}$ & GFS \\
\hline \multirow{3}{*}{ 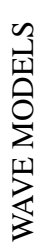 } & Ionian Sea & $\begin{array}{l}\text { WAM }\left(\text { Mediterranean }-0.25^{\circ} \times 0.25^{\circ}\right) \\
\text { WAM }\left(\text { Ionian Sea }-0.0625^{\circ} \times 0.0625^{\circ}\right)\end{array}$ & $\begin{array}{l}\text { BOLAM } \\
\text { MOLOCH }\end{array}$ \\
\hline & Maltese islands & $\begin{array}{l}\text { WAM }\left(\text { Mediterranean }-0.5^{\circ} \times 0.5^{\circ}\right) \\
\text { WAM }\left(\text { C. Mediterranean }-0.125^{\circ} \times 0.125^{\circ}\right)\end{array}$ & MARIA/ETA \\
\hline & Cyprus & $\begin{array}{l}\text { WAM }\left(\text { Mediterranean }-0.25^{\circ} \times 0.25^{\circ}\right) \\
\text { WAM }\left(\text { E. Mediterranean }-0.0625^{\circ} \times 0.0625^{\circ}\right)\end{array}$ & WRF \\
\hline
\end{tabular}

iii) For the application in the Malta area, the MARIA Malta Atmospheric forecasting system - consisting of a chain of meteo-marine models with downscaling to high resolution sub-domains - has been set up for the region north of $34^{\circ}$ latitude in the Sicilian Channel, and comprising of the Maltese Islands. The atmospheric forecasts are based on the ETA hydrostatic limited area grid point model with a "step-mountain" vertical coordinate system. The prognostic variables are temperature, wind ( $u$ and v components), specific humidity, surface pressure and turbulent kinetic energy. The downscaling of atmospheric conditions to the sub-regional scale is done by running the model in two nested steps with successively embedded model configurations down to a resolution of $1 / 24^{\circ}(\sim 5 \mathrm{~km})$ over the central Mediterranean area, and with outputs every $3 \mathrm{~h}$.

iv) For the application in Cyprus, the BOLAM model described by Buzzi et al. (1994, 1997, 1998) and Buzzi and Foschini (2000) is used. It is a hydrostatic model on an Arakawa $\mathrm{C}$ grid (rotated lat./lon. coordinates). BOLAM uses an explicit microphysical scheme with two water and three ice species similar to that of Schultz (1995) as well as the convective parameterization scheme proposed by Kain and Fritsch (1993), with implementation of the modifications suggested by Spencer and Stensrud (1998), as it concerns the delay of downdrafts in newly developed convection. For the operational implementation of BOLAM at the Cyprus Meteorological Service, two grids are used: the coarse grid with a $0.21^{\circ}$ horizontal grid interval $(\sim 23 \mathrm{~km})$, covering the area of the Eastern Mediterranean and the fine grid with $0.07^{\circ}$ horizontal grid interval $(\sim 7 \mathrm{~km})$, covering the area of Cyprus and the surrounding seas.

A summary of the operational features of the above models is presented in Table 1.

Another vital point for the construction of the EWS was the definition of the time interval of the warnings. Similarly to the weather forecasts, warnings covering of 24-h intervals, with no further time disaggregation, are likely to be successful but they are hardly ever helpful. On the other hand, warnings issued for very short time intervals (e.g. every 1 or $2 \mathrm{~h}$ ) may not be very accurate in time. Therefore, it was eventually decided to issue warnings for 6 -h intervals.

Thus, when the value of a meteorological parameter is forecast to exceed specific thresholds, at one or more grid points of a sub-region, during a 6 -h period, a yellow, orange or red warning is issued for this particular subregion, depending on the severity of the event. The warnings of precipitation (rain, snow, thunderstorm) refer to the 6-h period ending at the indicated time (e.g. a rainfall warning for the 21:00 local time (LT) refers to the period 15:0021:00 LT). The warnings for temperature and wind refer to the indicated validity time. When necessary, it is also possible to set two warnings for the same sub-area at the same time but no more than two in order to avoid confusing the public. For example, in a case of strong winds, snowfall and very low temperature forecast, only the first two warnings are presented as they are considered to be more significant inasmuch as the existence of a low temperature warning is indirectly inferred by snowfall. Some pairs of warnings have 
Table 2. The symbols of the weather alerts.

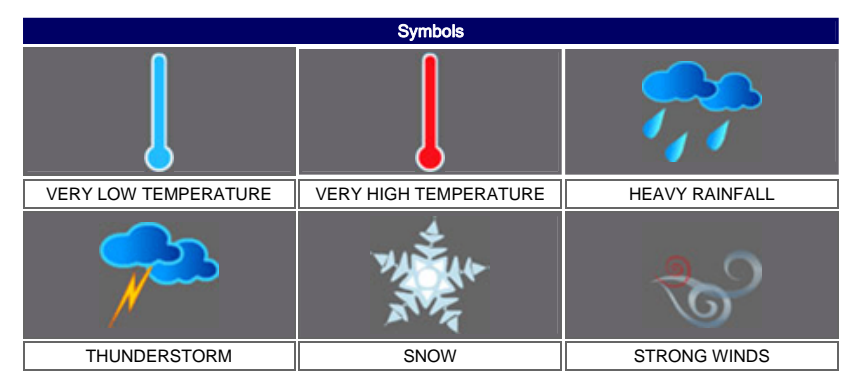

been excluded for similar reasons. For instance, snowfall at higher altitudes and rainfall at lower altitudes, in the same sub-area, are never reported together. Snowfall alone is reported since it is considered the more "hazardous" parameter. However, as this case is not an exceptional one but it is rather the rule, especially in mountainous sub-areas, some altitude thresholds have been set for snowfall alerts in order to avoid alarms referring to regions characterised by almost total absence of human activity. For example, in the very mountainous sub-areas of Epirus, with summits around $2500 \mathrm{~m}$, a snowfall alert is issued only when it is forecast to occur below $1000 \mathrm{~m}$, where most human activities take place. Similarly, a snowfall alert in the coastal sub-areas is set only in case of snow forecast below $400 \mathrm{~m}$.

Apart from the alert set, a critical point in an EWS is the way the alert is presented to the public. RISKMED offers a user-friendly graphical platform by utilizing six simple symbols, easily understandable by everybody. The six symbols are presented in Table 2 and they are displayed on a yellow, orange or red background indicating the level of the warning.

As previously mentioned, there is another series of alerts, byproducts of the weather forecast, which complete the EWS. These are alerts for human discomfort in cases of warm or cold spells (heat waves or cold outbreaks) and for weather conditions favouring fire spread (Table 3). For this reason, each partner has utilized a discomfort index as well as a fire weather index derived from its own forecast outputs (temperature, wind, humidity etc). For these indices, three thresholds of alerts have also been defined, similarly to the weather alerts. The formulas defined by the US National Weather Service have been adopted. The Wind chill Index is calculated based on wind speed and air temperature (Osczevski and Bluestein, 2005). The Heat Index computation is based on air temperature and relative humidity (Steadman, 1979). The Fosberg Fire Weather Index is calculated based upon equilibrium moisture content and wind speed; thus, its dependence is mainly on wind speed, relative humidity and temperature (Fosberg, 1978).

In parallel to the weather models, the WAM sea wave model is also operational to forecast wave height and direction. The WAM model, developed in the 80 s by an international group of scientists, is a well-established advanced third
Table 3. The symbols of the human discomfort and the fire weather alerts.

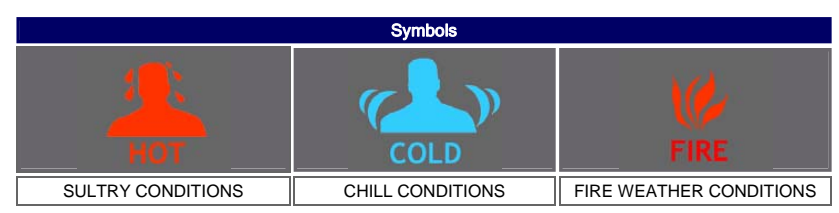

generation wave model. It is based on the spectral description (frequency and direction) of the wave conditions at the nodes of a grid covering the area of interest. Contrary to the previous models, the evolution of the spectra is evaluated only on the basis of physical principles (generation, nonlinear interactions, white capping), making the model suitable for application at both oceanic and local scales. It is presently used by most of the main meteorological and oceanographic centres around the world. A full description of its characteristics and performance can be found in Komen et al. (1994) and Janssen (2008). The requirement of the high resolution for a better evaluation of the meteorological and sea conditions led to the use of a nested procedure. One coarse grid has been used to cover the Mediterranean, which can be considered as a closed basin without any influence from the Atlantic Ocean, while for the Ionian Sea a higher resolution nested grid has been adopted. The results of the forecast cover $72 \mathrm{~h}$ and provide at 3 -h intervals the wave conditions with a resolution of about $7 \mathrm{~km}$.

Especially for the Sicilian Channel and the areas approaching the Maltese Islands, significant wave height is also used as a seventh alert with three levels. The wave forecasting system uses the 3rd generation WAM Cycle 4 spectral wave model. The model is forced by surface wind from the MARIA/ETA atmospheric model, and runs daily to produce a 72 -h forecast on a high-resolution grid $\left(1 / 8^{\circ}\right)$ over the region. The model set-up is based on the following run-time parameters: 30 frequencies (in the range from $0.041772 \mathrm{~Hz}$ to $0.662640 \mathrm{~Hz}$ ), 24 directions (every $15^{\circ}$ ), 3 output grids, 4916 sea points, and 3-h outputs. The main output parameters are: significant wave height, mean wave direction and frequency, and total sea state.

In Cyprus, the WAM model operates for the entire Mediterranean Sea. It is supported by the $10 \mathrm{~m}$ winds (grid length $0.5^{\circ}$ ) from the WRF atmospheric model and has a grid length of $0.25^{\circ}$ (soon it will also operate for an inner domain with a grid length of $0.0625^{\circ}$, covering the Seas around Cyprus). The model runs once daily based on 00:00 UTC initial data, and has a 3-h step and a forecast head of $72 \mathrm{~h}$. It has the ability to run from a cold environment, considering the wave height as zero, or from a warm environment considering a certain wave height in its initial state.

All the above products plus some more valuable information are presented in the official web page of the project as explained in the next section. 

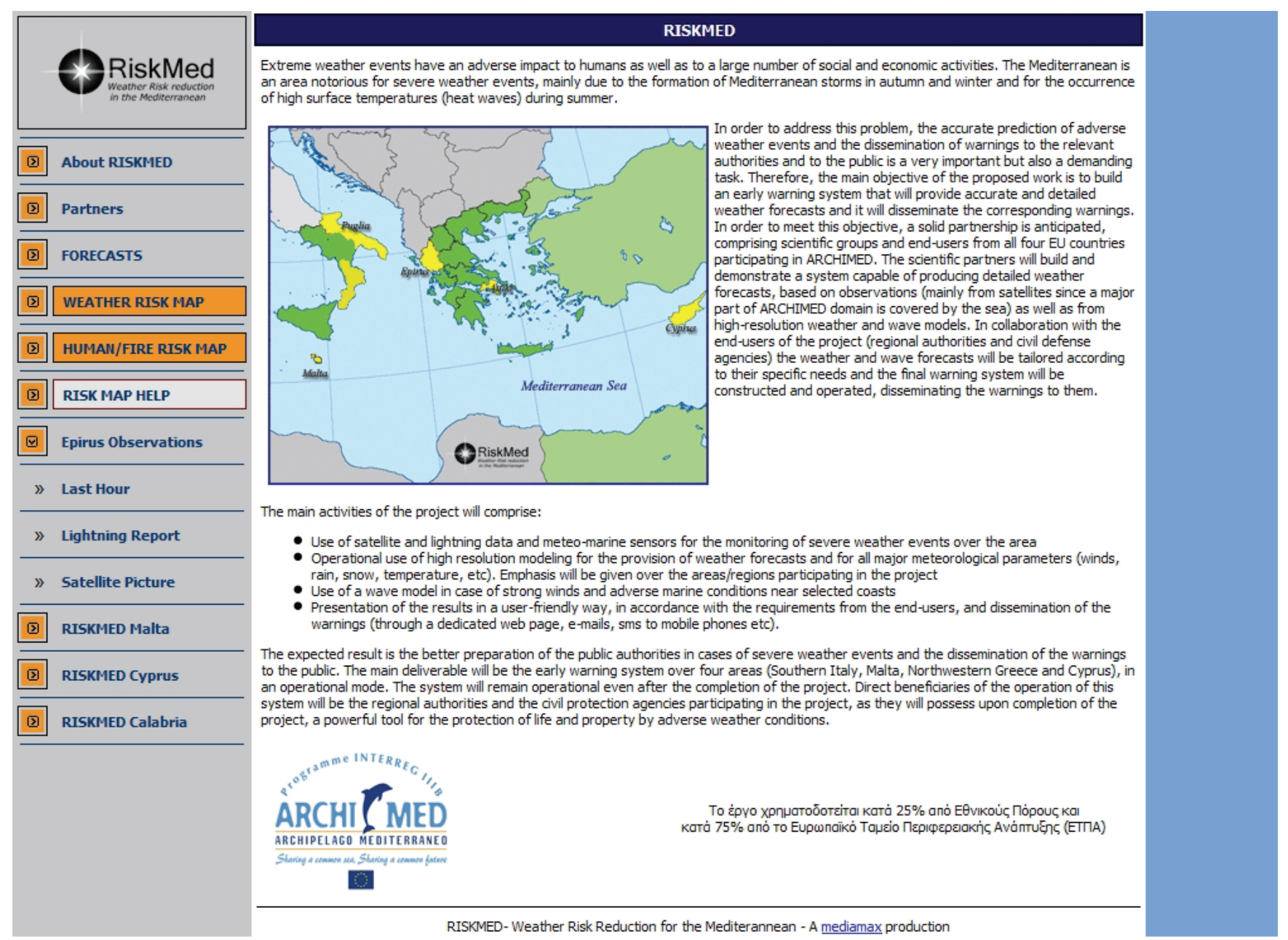

Fig. 2. The home page of the official web site of RISKMED (http://www.riskmed.net).

\section{Products}

On the web page of the project, http://www.riskmed.net, (Fig. 2) there are links for experienced meteorologists as well as for the public; viz. there is detailed scientific weather forecast information as well as some simplified information for users not familiar with meteorological terminology. From the main page, which is also the Greek page, the users can easily connect to other countries' websites, which are built on the same structure. The final RISKMED products, i.e. the EWS, are highlighted in orange on the left-hand side of the page. These are the RISK MAP, which exhibits the weather alerts and the HUMAN/FIRE RISK MAP, which exhibits the human discomfort and fire weather alerts. In Fig. 3, some examples of the RISK MAPS are presented for winter 20082009. In Fig. 3a (northwestern Greece), it is seen that there is an alert on each sub-area. These alerts may not be synchronous within the 48-h period forecast, but the user can easily see the time of the alerts as well as the following alerts for each sub-area by clicking on it. In the event that two simultaneous alerts are issued for the same sub-area, the corresponding symbols will be seen flashing on and off. In this example, strong winds are expected on the mountain Pindus range, low temperatures in the mountainous and inland subareas and heavy rainfall near the coasts. The rainfall alerts are issued at various levels as the rain symbol is presented either on a yellow, or on an orange or on a red background. The defined thresholds (in this case 8-, 15-, and 30- $\mathrm{mm} / 6-\mathrm{h}$, respectively) can be seen in the RISK MAP HELP link which is displayed under the EWS links. In the case of Fig. 3b (southern Italy), yellow wind and rain alerts are issued for the Ionian and the Adriatic Sea, yellow and orange rain alerts for Puglia, while no severe weather events are forecasted for Calabria and the Tyrrhenian Sea. Figure 3c (Malta) shows that yellow and orange wave alerts (2- and 3-m height, respectively) are issued for the seas while a yellow wind alert is issued for the Maltese Islands. In Fig. 3d (Cyprus), yellow thunderstorm warnings are issued for three sub-areas (5-12$\mathrm{mm} / 6$-h, with at least $50 \%$ of precipitation being convective), while all the levels of wind alert are displayed for the other 


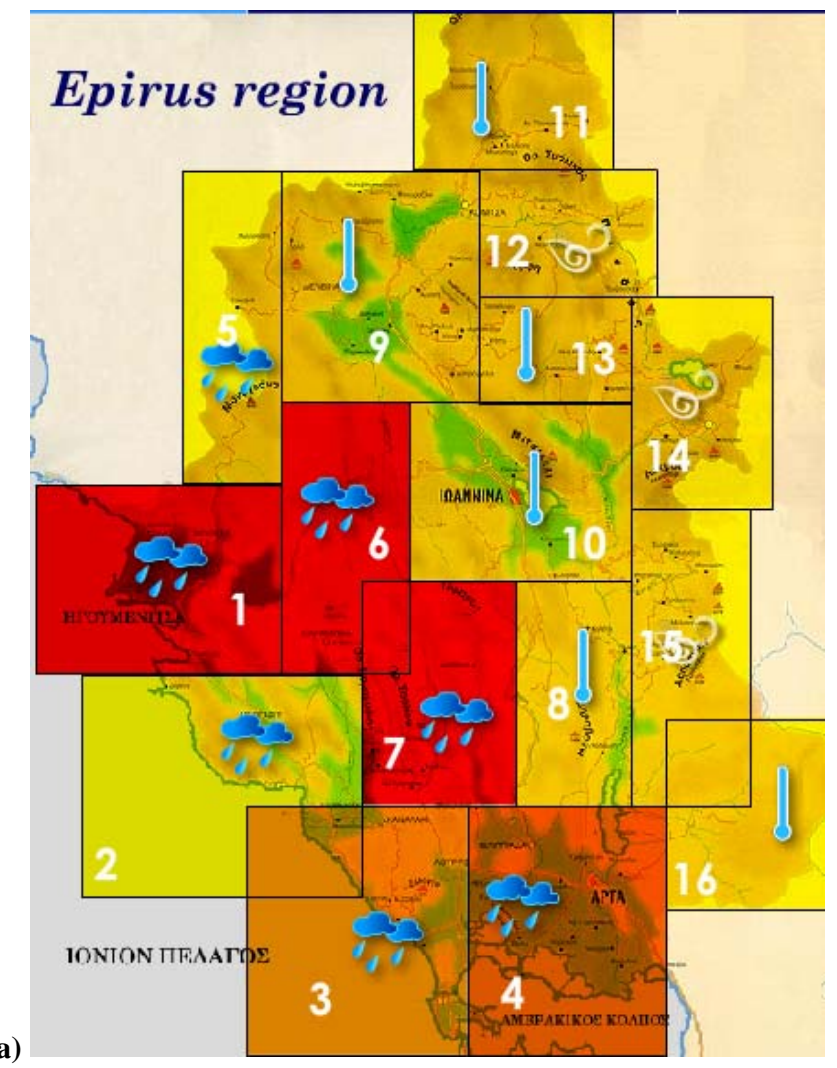

(a)

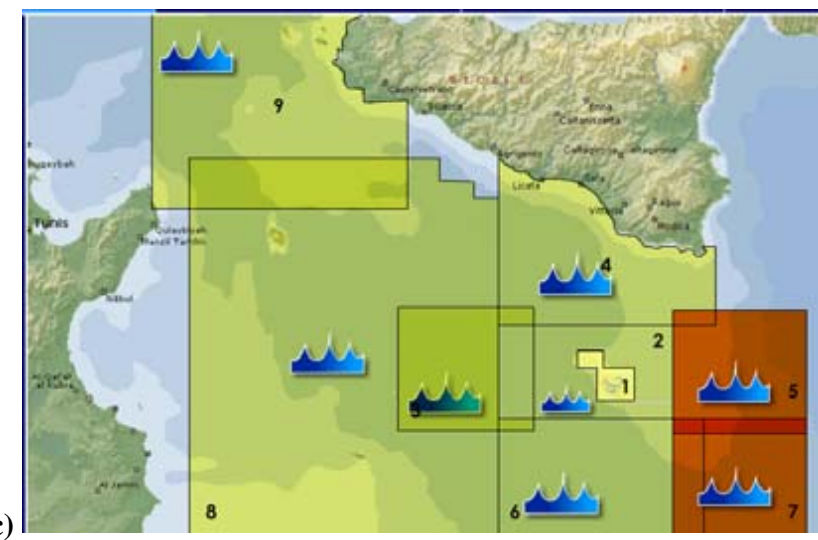

(b)

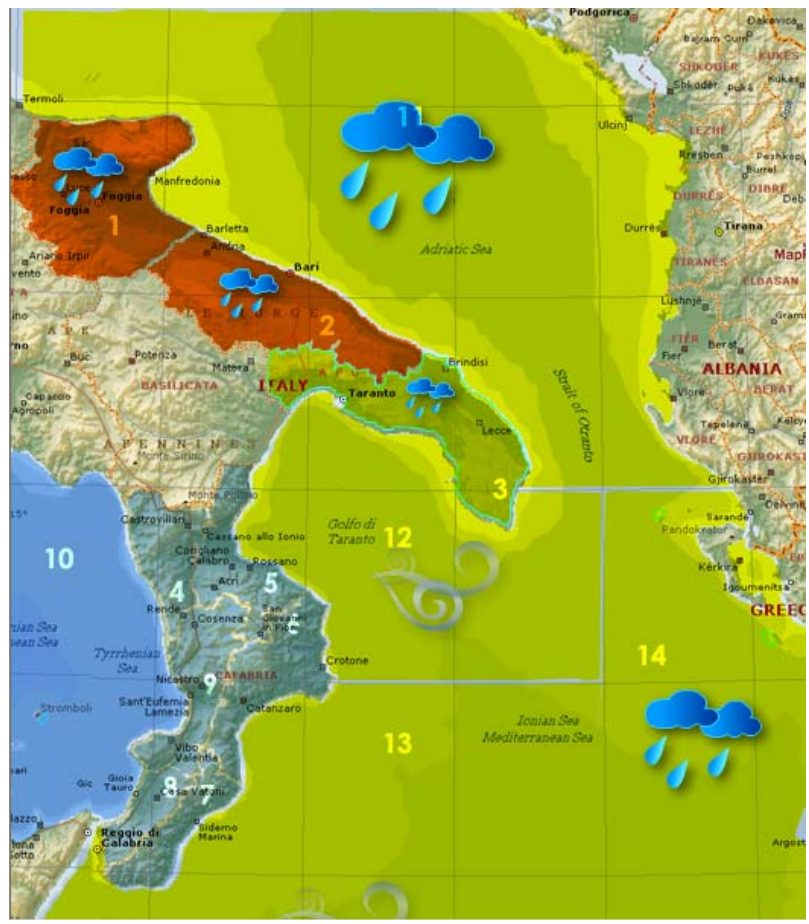

(d)

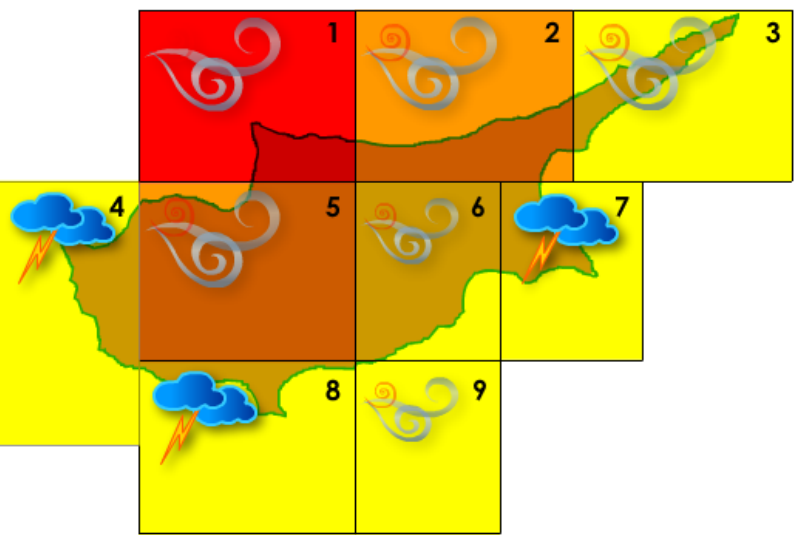

Fig. 3. Some winter examples of weather alerts for northwestern Greece (a), southern Italy (b), Malta (c), and Cyprus (d).

sub-areas (wind speed higher than 7, 8, and 9 Beauforts, respectively). As far as the human discomfort and the fire weather alerts are concerned, a summer 2009 example for Epirus is given in Fig. 4. It shows that human discomfort, arguably due to a heat wave, prevails in the southern subareas. Especially in the Arta region (sub-area 4), which is mainly inland, not directly neighbouring the Ionian Sea, the conditions are worse and, therefore, the alert is orange. In the sub-area 9, a yellow fire alert is generated, arguably due to a harmful combination of temperature, wind and humidity.

The RISKMED web page also hosts other useful meteorological information apart from the EWS alerts. The "forecast" link leads to numerous forecast meteorological maps over different domains (European, national, local) for the surface and the upper atmosphere. The accessible parameters are: sea level pressure, 10-m wind, 500-hPa geopotential height, $850-\mathrm{hPa}$ temperature, 300-hPa geopotential height and wind speed, cloud top temperature, and 6-h accumulated precipitation. In the same link, the WAM wave model results can also be found. An example of a wave height map for the Ionian Sea is given in Fig. 5. It is seen that rather high waves (significant wave height 5-6 $\mathrm{m}$ - deep orange colour) are approaching the coast of Calabria from the southeast, while lower waves (2-3 m - light green colour) are entering into the Adriatic Sea through the Otranto Strait. 


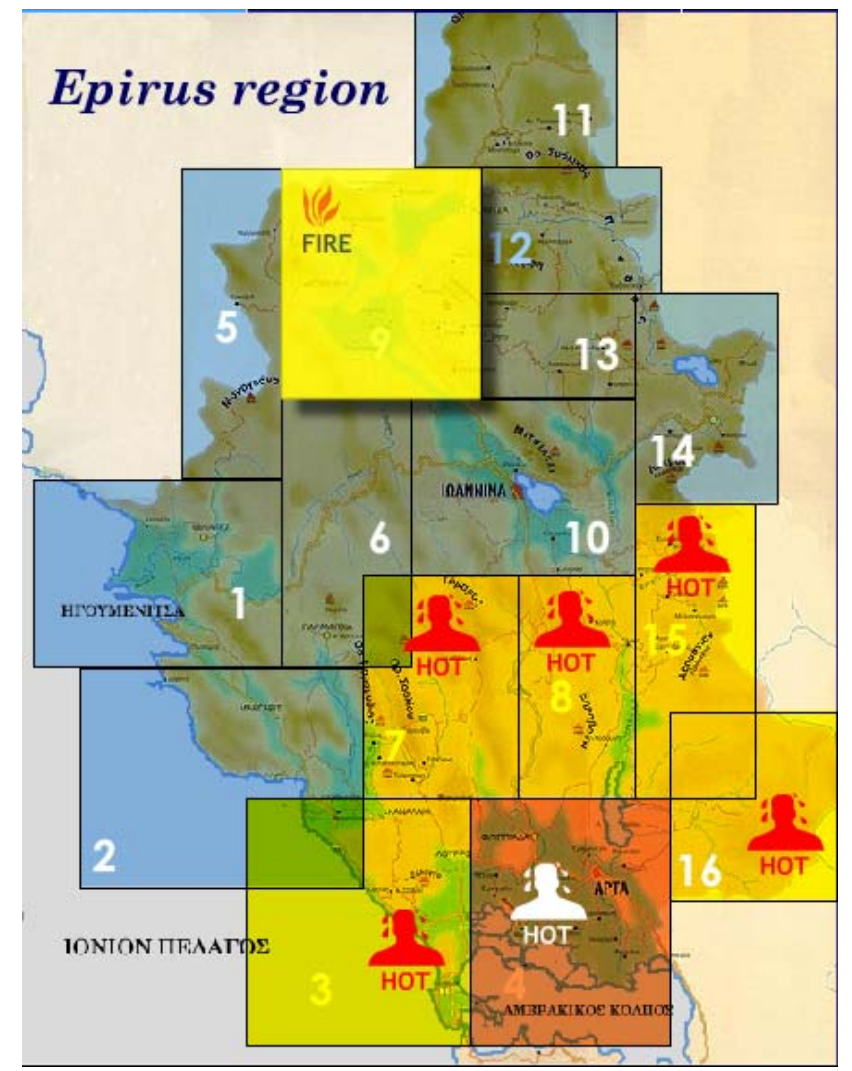

Fig. 4. A summer example of human discomfort and fire weather alerts for Epirus.

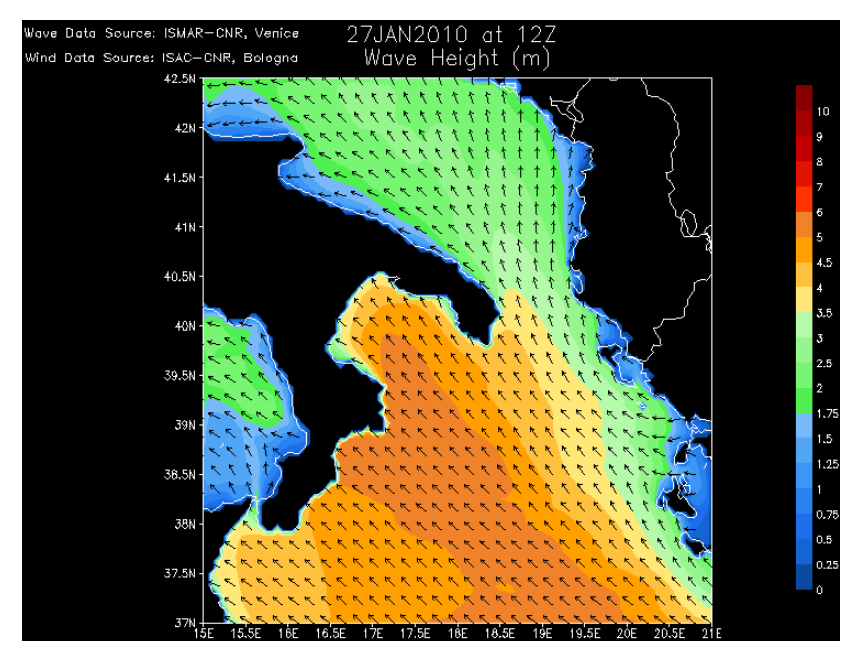

Fig. 5. An example of the WAM wave height model output for the Ionian Sea.

Beside the forecasts, real-time data from the lightning detection system ZEUS, which is operated by the National Observatory of Athens (Kotroni et al., 2008; Lagouvardos et al., 2009), is also displayed for each country (figure not shown). Also, a series of real-time or last-hour surface ob- servations (temperature, wind and weather phenomena) from automatic and manned weather stations over the area of application are presented. Finally, the latest satellite picture over the Mediterranean from the METEOSAT Second Generation satellite of EUMETSAT is available.

\section{Conclusions}

RISKMED EWS constitutes an innovative tool available to the staff of regional authorities and civil protection agencies of the areas involved in the project, implemented in order to facilitate their duty. It provides the end-users with state-of-the-art-accurate information about the time and place of a potential hazard provoked by adverse weather conditions. The social benefits to be had from the operational use of the early warning system are straightforward, not only for the local population but also for the economic life of the regions (transportation, agriculture, tourism, etc.). Such benefits are expected to further increase since the system has remained operational after the completion of the programme. Moreover, this prolonged operation will also serve to demonstrate the system to the authorities of other European regions who may eventually implement a similar system themselves.

Acknowledgements. This work was supported by RISKMED project, Programme INTERREG IIIB-ARCHIMED.

Edited by: F. Guzzetti

Reviewed by: two anonymous referees

\section{References}

Akylas, E., Kotroni, V., and Lagouvardos, K.: Sensitivity of high resolution operational weather forecasts to the choice of the planetary boundary layer scheme, Atmos. Res., 84, 49-57, 2007.

Auld, H.: Disaster risk reduction under changing climate conditions: roles for the national meteorological and hydrological services, WMO Bulletin, 57(2), 118-125, 2008.

Bartzokas, A., Kotroni, V., Lagouvardos, K., Lolis, C. J., Gkikas, A., and Tsirogianni, M. I.: Weather forecast in northwestern Greece: RISKMED warnings and verification of MM5 model, Nat. Hazards Earth Syst. Sci., 10, 383-394, doi:10.5194/nhess10-383-2010, 2010.

Bertotti, L. and Cavaleri, L.: Large and small scale wave forecast in the Mediterranean Sea, Nat. Hazards Earth Syst. Sci., 9, 779788, doi:10.5194/nhess-9-779-2009, 2009.

Bertotti, L., Miglietta, M. M., and Davolio, S.: Coupling of highresolution meteorological and wave models over southern Italy, Nat. Hazards Earth Syst. Sci., 9, 1267-1275, doi:10.5194/nhess9-1267-2009, 2009.

Buzzi, A., Fantini, M., Malguzzi, P., and Nerozzi, F.: Validation of a limited area model in cases of Mediterranean cyclogenesis: surface fields and precipitation scores, Meteorol. Atmos. Phys., 53, 137-153, 1994.

Buzzi, A., Cadelli, R., and Malguzzi, P.: Low level jet simulation over the Antarctic ocean, Tellus A, 49, 263-276, 1997. 
Buzzi, A., Tartaglione, N., and Malguzzi, P.: Numerical simulations of the 1994 Piedmont flood: role of orography and moist processes, Mon. Weather Rev., 126, 2369-2383, 1998.

Buzzi, A. and Foschini, L.: Mesoscale meteorological features associated with heavy precipitation in the southern Alpine region, Meteorol. Atmos. Phys., 72, 131-146, 2000.

Casella, D., Dietrich, S., Di Paola, F., Formenton, M., Mugnai, A., Porcù, F., and Sanò, P.: A combined IR-MW technique for frequent estimation of convective rain areas from satellite, Nat. Hazards Earth Syst. Sci., in preparation, 2010.

Davolio, S., Buzzi, A., and Malguzzi, P.: High resolution simulations of an intense convective precipitation event, Meteorol. Atmos. Phys., 95, 139-154, 2007.

Davolio, S., Miglietta, M. M., Moscatello, A., Pacifico, F., Buzzi, A., and Rotunno, R.: Numerical forecast and analysis of a tropical-like cyclone in the Ionian Sea, Nat. Hazards Earth Syst. Sci., 9, 551-562, doi:10.5194/nhess-9-551-2009, 2009.

Dietrich, S., Di Paola, F., Casella, D., Formenton, M., Mugnai, A., and Sanò, P.: A lightning-based algorithm to propagate convective rain fields retrieved from passive-microwave satellite measurements, Nat. Hazards Earth Syst. Sci., in preparation, 2010.

Drago, A., Music, S., Azzopardi, J., and Gauci. A.: An Prototype Early Atmospheric Warning System for the Maltese Islands and the Central Mediterranean area, Nat. Hazards Earth Syst. Sci., in preparation, 2010.

Dudhia, J.: A non-hydrostatic version of the Penn State/NCAR mesoscale model: validation tests and simulation of an Atlantic cyclone and cold front, Mon. Weather Rev., 121, 1493-1513, 1993.

Fosberg, M. A.: Weather in wildland fire management: the fire weather index, in: Proceedings of the Conference on Sierra Nevada meteorology, Lake Tahoe, California, USA, Amer. Meteor. Soc., Boston, 1-4, 19-21 June 1978.

Hong, S. Y. and Pan, H. L.: Nonlocal boundary layer vertical diffusion in a medium-range forecast model, Mon. Weather Rev., 124, 2322-2339, 1996.

Janssen, P. A. E. M.: Progress in ocean wave forecasting, J. Comput. Phys., 227(7), 3572-3594, 2008.

Kain, J. S. and Fritsch, J. M.: Convective parameterization for mesoscale models: the Kain-Fritsch scheme. The Representation of Cumulus in numerical models, American Meteorological Society, Meteor. Monogr., No 46, 165-177, 1993.

Komen, G. J., Cavaleri, L., Donelan, M., Hasselmann, K., Hasselmann, S., and Janssen, P. A. E. M.: Dynamics and modelling of ocean waves, Cambridge University Press, Cambridge, 532 pp., 1994.

Kotroni, V. and Lagouvardos, K.: Precipitation forecast skill of different convective parameterization and microphysical schemes: application for the cold season over Greece, Geophys. Res. Lett., 108, 1977-1980, 2001.

Kotroni, V. and Lagouvardos, K.: Evaluation of MM5 highresolution real-time forecasts over the urban area of Athens, Greece, J. Appl. Meteorol., 43, 1666-1678, 2004.

Kotroni, V. and Lagouvardos, K: Lightning occurrence in relation with elevation, terrain slope and vegetation cover over the Mediterranean, J. Geophys. Res.-Atmos., 113, D21118, doi:10.1029/2008JD010605, 2008.
Lagouvardos, K., Kotroni, V., Betz, H.-D., and Schmidt, K.: A comparison of lightning data provided by ZEUS and LINET networks over Western Europe, Nat. Hazards Earth Syst. Sci., 9, 1713-1717, doi:10.5194/nhess-9-1713-2009, 2009.

Michalakes, J., Dudhia, J., Gill, D., Henderson, T., Klemp, J., Skamarock, W., and Wang, W.: The Weather Research and Forecast Model: Software Architecture and Performance, in: Proceedings of the 11th ECMWF Workshop on the Use of High Performance Computing In Meteorology, 25-29 October 2004, Reading, UK, edited by: Zwieflhofer, W. and Mozdzynski, G., World Scientific, 156-168, 2005.

Miglietta, M. M. and Regano, A.: An observational and numerical study of a flash-flood event over south-eastern Italy, Nat. Hazards Earth Syst. Sci., 8, 1417-1430, doi:10.5194/nhess-8-1417-2008, 2008.

Mugnai, A., Casella, D., Cattani, E., Dietrich, S., Di Paola, F., Formenton, M., Laviola, S., Levizzani, V., and Sanò, P.: Precipitation retrieval from combined microwave/infrared satellite observations of thunderstorms over the Mediterranean area, Nat. Hazards Earth Syst. Sci., in preparation, 2010.

Novac, P.: The Czech hydrometeorological institute's severe storm nowcasting system, Atmos. Res., 83, 450-457, 2007.

Osczevski, R. and Bluestein, M.: The New Wind Chill Equivalent Temperature Chart, B. Am. Meteorol. Soc., 86, 1453-1458, 2005.

Price, C., Yair, Y., Mugnai, A., Lagouvardos, K., Llasat, M. C. and Michaelides, S.: Results from the EU FLASH project: The link between flash floods and lightning flashes, EGU General Assembly 2010, Vienna, Austria, 2-7 May 2010.

Rauhala, J. and Schultz, D. M.: Severe thunderstorm and tornado warnings in Europe, Atmos. Res., 93, 369-380, 2009.

Savvidou, K., Michaelides, S., Nicolaides, K. A., and Constantinides, P.: Presentation and preliminary evaluation of the operational Early Warning System in Cyprus, Nat. Hazards Earth Syst. Sci., 9, 1213-1219, doi:10.5194/nhess-9-1213-2009, 2009.

Schultz, P.: An explicit cloud Physics parametrization for operational numerical weather prediction, Mon. Weather Rev., 123, 3331-3343, 1995.

Skamarock, W. C., Klemp, J. B., Dudhia, J., Gill, D. O., Barker, D. M., Wang, W., and Powers, J. G.: A Description of the Advanced Research WRF Version, NCAR Tech. Note 468STR, 88 pp. 2005.

Spencer, P. L. and Stensrud, D. J.: Simulating flash flood events: Importance of the subgrid representation of convection, Mon. Weather Rev., 126, 2884-2912, 1998.

Steadman, R. G.: The assessment of sultriness. Part I: A temperature-humidity index based on human physiology and clothing science, J. Appl. Meteorol., 18, 861-873, 1979.

Thompson, G., Rasmussen, R. M., and Manning, K.: Explicit forecasts of winter precipitation using an improved bulk microphysics scheme. Part I: Description and sensitivity analysis, Mon. Weather Rev., 132, 519-542, 2004.

Yair, Y., Lynn, B., Price, C., Kotroni, V., Lagouvardos, K., Morin, E., Mugnai A., and Llasat, M.-C.: Predicting the potential for lightning activity in Mediterranean storms based on the Weather Research and Forecasting (WRF) model dynamic and microphysical fields, J. Geophys. Res.-Atmos., 115, D04205, doi:10.1029/2008JD010868, 2010. 